Article

\title{
Small-Sized Pulsating Heat Pipes/Oscillating Heat Pipes with Low Thermal Resistance and High Heat Transport Capability
}

\author{
Markus Winkler ${ }^{1, *}$, David Rapp ${ }^{1}$, Andreas Mahlke ${ }^{1}$, Felix Zunftmeister ${ }^{1}$, Marc Vergez ${ }^{1}$, \\ Erik Wischerhoff $^{2}$, Jürgen Clade ${ }^{3}$, Kilian Bartholomé ${ }^{1}$ (D) and Olaf Schäfer-Welsen ${ }^{1}$ \\ 1 Fraunhofer Institute for Physical Measurement Techniques IPM, Heidenhofstraße 8, 79110 Freiburg, \\ Germany; davidrapp.guitar@googlemail.com (D.R.); andreas.mahlke@ipm.fraunhofer.de (A.M.); \\ felix.zunftmeister@googlemail.com (F.Z.); marc.vergez@ipm.fraunhofer.de (M.V.); \\ Kilian.Bartholome@ipm.fraunhofer.de (K.B.); olaf.schaefer-welsen@ipm.fraunhofer.de (O.S.-W.) \\ 2 Fraunhofer Institute for Applied Polymer Research IAP, Geiselbergstraße 69, 14476 Potsdam, Germany; \\ erik.wischerhoff@iap.fraunhofer.de \\ 3 Fraunhofer Institute for Silicate Research ISC, Neunerpl. 2, 97082 Würzburg, Germany; \\ juergen.clade@isc.fraunhofer.de \\ * Correspondence: markus.winkler@ipm.fraunhofer.de; Tel.: +49-761-8857611
}

Received: 26 February 2020; Accepted: 1 April 2020; Published: 5 April 2020

\begin{abstract}
Electronics (particularly power electronics) are the core element in many energy-related applications. Due to the increasing power density of electronic parts, the demands on thermal management solutions have risen considerably. As a novel passive and highly efficient cooling technology, pulsating heat pipes (PHPs) can transfer heat away from critical hotspots. In this work, we present two types of small and compact PHPs with footprints of $50 \times 100 \mathrm{~mm}^{2}$, thicknesses of 2 and $2.5 \mathrm{~mm}$ and with high fluid channel density, optimized for cooling electronic parts with high power densities. The characterization of these PHPs was carried out with a strong relation to practical applications, revealing excellent thermal properties. The thermal resistance was found to be up to $90 \%$ lower than that of a comparable solid copper plate. Thus, a hot part with defined heating power would remain at a much lower temperature level and, for the same heater temperature, a much larger heating power could be applied. Moreover, the dependence of PHP operation and thermal properties on water and air cooling, condenser area size and orientation is examined. Under some test configurations, dryout conditions are observed which could be avoided by choosing an appropriate size for the fluid channels, heater and condenser.
\end{abstract}

Keywords: pulsating heat pipes; oscillating heat pipes; cooling; heat transfer; thermal resistance; electronics cooling

\section{Introduction}

Power levels and power densities in electronic devices are greatly increasing and can reach several $100 \mathrm{~W} / \mathrm{cm}^{2}$. Consequently, moving, spreading and rejecting waste heat in order to prevent overheating of these devices is becoming increasingly challenging. Passive thermal control solutions are generally preferable since they are technically simple, more reliable and often cheaper than active solutions such as water cooling. As an emerging passive technology, pulsating heat pipes (PHPs), also called oscillating heat pipes (OHPs) [1,2], can be a very efficient thermal solution to remove the heat from critical hotspots. The basic concept of PHPs was introduced by Akachi in 1990. PHPs consist of meandering channels which are partially filled with a working fluid which moves in an oscillatory or pulsating fashion to efficiently transfer heat. For their operation, only a certain thermal gradient 
between the hot side (evaporator) and cold side (condenser) is required. The thermal gradient $d T$ results in a vapor pressure difference $d P$ between the hot side and cold side, which is the driver of the fluid motion. In contrast to conventional heat pipes (HPs), PHPs do not require a wick to move the fluid back to the hot side and the majority of heat is carried by sensible heat, rather than latent heat [2]. PHPs can be made in the form of compact flat plates with integrated channels and thicknesses of a few millimeters, facilitating integration together with electronic components. Typically, they can reach effective thermal conductivities that are much larger than those of the container materials (typically copper or aluminum) and can handle heat fluxes of up to $300 \mathrm{~W} / \mathrm{cm}^{2}$ [3]. Extensive experimental and theoretical investigations were carried out to better understand fluid flow and heat transfer mechanisms in PHPs, resulting in a large number of publications (e.g., [1-8]). An overview over the current state of the art is given in [1,2] and, most recently, in [9]. Six major parameters were identified which primarily determine the system dynamics and performance [10]. These parameters are: i) internal channel diameter, ii) filling ratio of the working fluid, iii) input heat flux, iv) total number of turns, v) device orientation (with respect to gravity) and vi) the thermo-physical properties of the working fluid, particularly the vapor pressure change with temperature, $d P / d T$.

The influence of these properties was analyzed in a significant number of publications and PHPs with very good thermal transport properties were often achieved. However, in many cases, rather large, complicated or impractical designs of PHPs were used. For example Taft, Takawale, Yang, Laun and Thompson, respectively, showed results for PHPs with footprints as large as $250 \times 250 \mathrm{~mm}^{2}$ [11], $200 \times 350 \mathrm{~mm}^{2}$ [12], $180 \times 120 \mathrm{~mm}^{2}$ [10], $100 \times 100 \mathrm{~mm}^{2}$ [13] and $75 \times 136 \mathrm{~mm}^{2}$ [7]. Other examples of PHPs consist of round bent tubes instead of flat plates, which makes it difficult to establish a good thermal connection to flat semiconductor devices.

For application in power electronics (which is the core element in many different energy-related applications), a flat, simple, compact and small-size PHP design is highly preferable. Therefore, in this work, we present PHPs with a footprint of only $50 \times 100 \mathrm{~mm}^{2}$ and a thickness of only 2 and $2.5 \mathrm{~mm}$. Despite their small size, the PHPs have excellent thermal transport and heat spreading capabilities. The PHPs are made of copper, enabling the use of joining technology that is standard in (power) electronics. Furthermore, the PHPs were developed, built and characterized under different conditions, which are close to practical applications, e.g., with water cooling as well as air cooling at the cold (i.e., condenser) side. For characterization, a ceramic heater is used to mimic a heat-generating component from power electronics.

\section{Experimental Setup}

\subsection{Structure of Examined PHPs}

The fabricated PHPs were specifically designed to accommodate a large number of channels on a fixed footprint of $50 \times 100 \mathrm{~mm}^{2}$. The reason is that as the number of channels increases, so does the internal pertubation in terms of bubble growth and collapse [10], which is one of the basic processes governing PHP activity and performance. Additionally, the higher level of local perturbations helps to avoid vapor phase recoiling in the evaporator and liquid merging in the condenser [14]. From this, it can be concluded that PHPs with a larger number of channels are likely to work in a more "stable" way, as the pulsating motion can be sustained for a larger range of input powers. A high channel density is also supposed to facilitate startup of the heat pipe, i.e., achieving the desired pulsating motion of the fluid and vapor segments already at relatively low heating powers. As a further advantage, it reduces the gravity dependence of PHP operation, which means that a PHP can work well in both vertical and horizontal orientation with respect to gravity—see, e.g., [1] (p. 212) and [15]. Finally, a high channel density can also prevent or delay the standstill of PHP operation, which can be caused by insufficient amounts of liquid returning to the evaporator at large heating powers, a condition also known as "dryout". In this case, all liquid slugs and/or liquid films in the heating zone, i.e., evaporator area, are completely evaporated, the evaporator area is completely dry [16] and no heat can be transferred 
from the evaporator via the liquid. This state should be avoided since it causes the temperature to rise abruptly, endangering the integrity of the PHP and thereby the parts to be cooled. Besides the number of channels, their size also has to be considered. If the channel diameters are too small, the flow resistance strongly increases, which can stall the fluid motion and reduce the overall heat throughput capacity [10]. The upper limit of the channel size, in turn, is given by the Bond number criterion (see, e.g., $[1,2])$, above which no liquid plugs can be formed.

Taking into account these considerations, channel sizes of $1 \times 1 \mathrm{~mm}^{2}$ and $1.5 \times 1.5 \mathrm{~mm}^{2}$ were finally chosen. The channels were fabricated by milling half-channels of $1.0 \times 0.5 \mathrm{~mm}^{2}$ and $1.5 \times 0.75$ $\mathrm{mm}^{2}$ into two separate copper plates that were later joined by brazing. The resulting channel structure of the fabricated PHP with 20 channels, with a channel size of $1.5 \times 1.5 \mathrm{~mm}^{2}$, is shown in Figure 1 . The total thickness of this PHP was $2.5 \mathrm{~mm}$. The PHP with $1 \times 1 \mathrm{~mm}^{2}$ channels had a total of 26 channels and its total thickness was $2 \mathrm{~mm}$. For filling, a copper tube was attached to the PHP. Acetone was used as a working fluid with a filling ratio of approximately $50 \%$ for both channel sizes. The filling was carried out at a base pressure of $1.3 \times 10^{-3}$ mbar measured at the inlet of the mentioned filling tube (not in the PHP itself). The fluid was thoroughly degassed prior to filling.
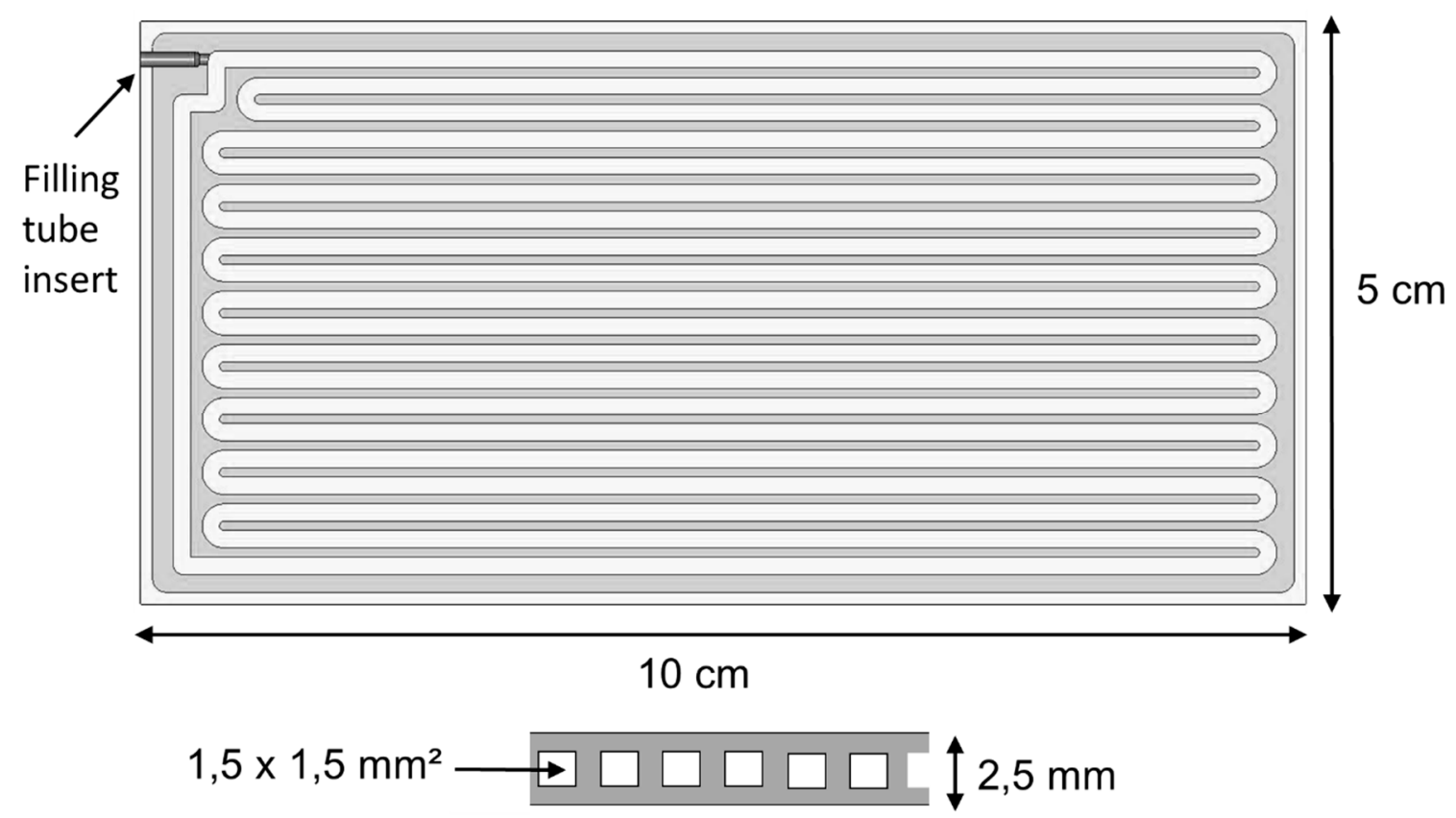

Figure 1. Channel structure and dimensions $\left(50 \times 100 \times 2.5 \mathrm{~mm}^{3}\right)$ of fabricated pulsating heat pipe (PHP) with channel size of $1.5 \times 1.5 \mathrm{~mm}^{2}$. Top: top view. Bottom: cross section showing channel structure.

\subsection{Setup for Characterization of PHPS}

The basic characteristic of a PHP is its thermal resistance:

$$
R_{t h}=\frac{\Delta T}{\grave{Q}}
$$

where $Q$ is the heating power or heat flow and $\Delta T$ is the temperature difference measured along the heat flow at defined positions on the PHP with thermocouples. In addition, the heater temperature $T_{H}$ in dependence of $Q$ is of general interest. The setups used for the measurement of these properties are described below. 


\subsubsection{PHP Characterization with Water Cooling at the Condenser Zone}

The characterization of the PHPs with water cooling was carried out with the "test bench" setup shown in Figure 2. The bench can be aligned in different orientations with respect to gravity. The PHPs were characterized in horizontal as well as vertical orientation. In vertical orientation, the long axis of the PHP was perpendicular to the ground level and parallel to the gravitational force, the heater (evaporator) was placed at the bottom of the PHP and the condenser was at the top of the PHP (an arrangement also known as "bottom heat mode"). A ceramic heater with a width $b$ of $8 \mathrm{~mm}$, i.e., a footprint of $8 \times 50 \mathrm{~mm}^{2}\left(\mathrm{Si}_{3} \mathrm{~N}_{4}\right.$, Bach Resistor Ceramics) defining the evaporator zone, was pressed onto the PHP by a hold-down clamp that consists of a screw head, spring, brass rod, metal bar and Teflon spacer block. The cooling (i.e., removal of the heat generated by the heat source) at the condenser zone of the PHP was achieved by means of a copper plate with a footprint of $14 \times 50 \mathrm{~mm}^{2}$ (i.e., width $L$ of $14 \mathrm{~mm}$ ) and a height of $2 \mathrm{~mm}$. For another specific experiment (Section 3.2.3.), aiming to vary the condenser area, different condenser plates with a width ranging from 10 to $50 \mathrm{~mm}$ were used together with a heater width of $25 \mathrm{~mm}$.

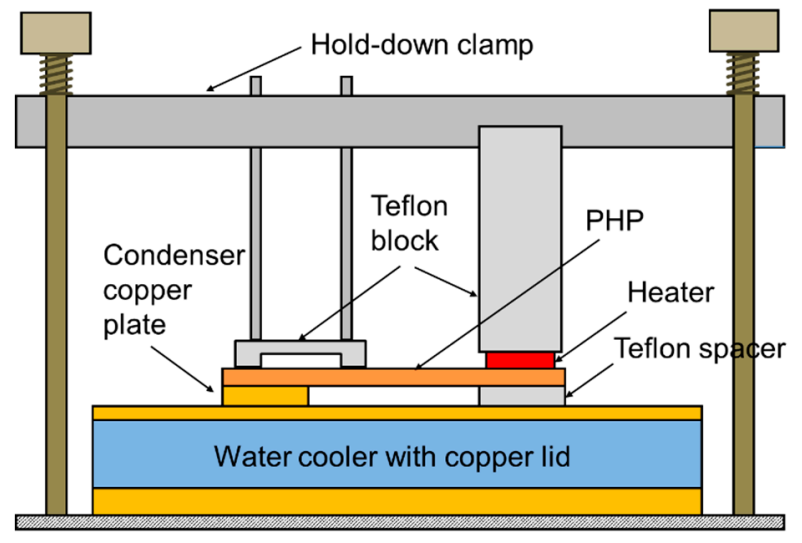

(a)

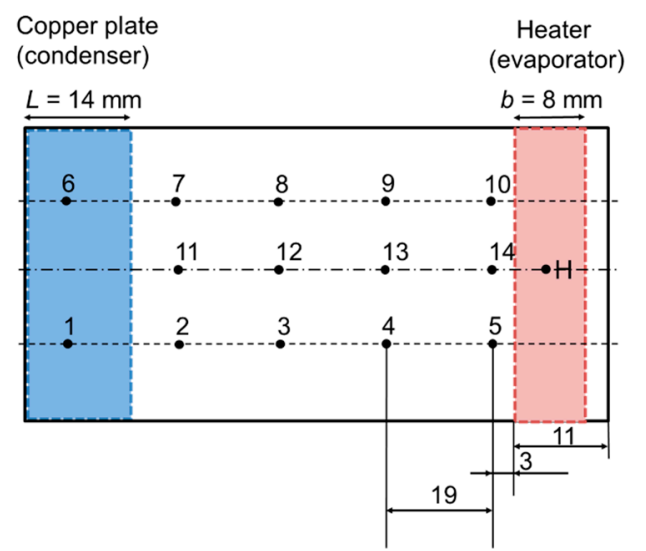

(b)

Figure 2. Measurement setup used for the characterization of the PHP with water cooling at the condenser zone. (a) Test bench, (b) positions of thermocouples and of copper plate (condenser zone) and heater (evaporator zone). Thermocouples 1-5 and 6-10 are arranged in one line on the top side of the PHP and 11-14 are arranged on one line at the bottom side. H represents the thermocouple directly inserted into the heater.

The condenser copper plate was in thermal contact with a water cooler made of copper. Cooling water with a constant temperature of $20.5{ }^{\circ} \mathrm{C}$ was provided by a circulating chiller (Lauda WK230). Thermal paste was applied to the interfaces of the heat-carrying parts, i.e., to the bottom of the heater and to both sides of the condenser copper plate (WLPK10, Fischer Elektronik). A Teflon spacer of the same height as the condenser copper plate was inserted between PHP and the water cooler to prevent the PHP from tilting and thus ensure its good thermal contact with the cooling copper plate and the heater. To further enhance thermal contact, a second U-shaped Teflon spacer close to the copper plate was added to the hold-down clamp setup. In order to minimize parasitic heat flows, the contact area to each of the Teflon spacers was minimized by carving slits into the spacers. The whole setup was isolated by rock wool (ROCKWOOL 800).

A power supply (Elektro-Automatik EA-PS 8065-10) was used to generate a well-defined electrical power $P_{e l}$ for the heater. Parasitic heat flows due to thermal radiation, convection and conduction through the Teflon spacers were estimated to be in the order of ca. $10 \%$ of the total heat flux. This estimation was made using the assumed typical PHP temperatures during the tests, the materials and geometry of the setup and the difference between simulated and measured data of a reference copper plate with known properties. As a result, it was assumed that the electrical power applied 
to the heater is in accordance with the heat flux through the PHP, i.e., $Q \simeq P_{e l}$. For fixed heating powers $Q$, the temperature of the PHP was measured by type K thermocouples (OMEGA Engineering, wire diameter of $80 \mu \mathrm{m}$ and Teflon insulation). A total of 14 thermocouples (Figure 2, $T_{i}$ numbered with $i=1-14)$ was used. The thermocouples were arranged in three lines, two on top of the PHP and one at the bottom. We note that special care was taken to precisely place the thermocouples at exactly predefined positions (i.e., at the same position for each PHP/copper plate and each comparable test run) in order to yield reproducible results. For this, an identical "placement grid" was drawn on each sample using a pen and a ruler before the thermocouples were attached. We estimate the uncertainty of the thermocouple placement at ca. $0,8 \mathrm{~mm}$. The temperature $T_{i}$ at each thermocouple location was acquired by averaging the measured temperatures over several minutes after temperature equilibration. From the temperatures $T_{i}$ and $T_{i+1}$ of neighbouring thermocouples situated on the same line, the relevant temperature differences $\Delta T_{j}=T_{i+1}-T_{i}$ were calculated, resulting in 11 values for $\Delta T_{j}$. These values were averaged to yield the average $\Delta{ }^{\prime} T=\frac{1}{N} \sum_{j=1}^{N} \Delta T_{j} . \Delta T$ was used for the calculation of $R_{t h}$ as shown in Equation (1). The uncertainty of $R_{t h}$ was assumed to be dominated by the uncertainty on the measured temperature differences, which is the sample standard deviation as defined by $\delta(\Delta T)=\frac{1}{\sqrt{N}} \sqrt{\frac{\sum_{j=1}^{N}\left(\Delta T_{j}-\Delta T\right)^{2}}{N-1}}$ with $N=11$ as number of values for $\Delta T_{j}$ and $\Delta^{\prime} T$ as the average of all 11 obtained values of $\Delta T_{i}$. In addition to the thermocouples on the PHP used to calculate $\Delta T_{j}$, a separate sheathed thermocouple was inserted into a hole drilled into the heater to measure the heater temperature $T_{H}$. The uncertainty on $T_{H}$ corresponds to the typical uncertainty for type $\mathrm{K}$ thermocouples of about $1.5 \mathrm{~K}$. Error bars in the respective graphs are omitted for better readability. Due to safety reasons (avoiding excessive vapor pressure of the working fluid which might damage the PHP) a maximum safe heater temperature of $140{ }^{\circ} \mathrm{C}$ was preset in all experiments, and the experiment was quickly aborted when the heater temperature exceeded this temperature.

In addition to the properties obtained for PHP, the respective plots also contain measured values of $R_{t h}$ and $T_{H}$ for a solid full copper plate of the same dimension as the examined PHP, i.e., $50 \times 100 \times$ $2.5 \mathrm{~mm}^{3}$ for the PHP with $1.5 \times 1.5 \mathrm{~mm}^{2}$ channels and $50 \times 100 \times 2.0 \mathrm{~mm}^{3}$ for the PHP with $1 \times 1 \mathrm{~mm}^{2}$ channels. The same setup was used for PHP and copper plate. Since, in the case of the copper plate, there was only negligible scattering in $R_{t h}$ for all applied heating powers, we represent these values as a line giving the average $R_{t h}$.

\subsubsection{PHP Characterization with Air Cooling at the Condenser Zone}

Due to their lower complexity and cost, air-based cooling systems are preferred to water-based systems in many applications. Therefore, a separate setup (Figure 3, conceptually similar to the setup shown in Figure 2) was assembled, which allowed us to test the PHPs in connection with an air cooled aluminum heat sink (Fischer Elektronik, LAM 550 24) in the condenser zone. The heat sink with dimensions of $50 \times 50 \times 50 \mathrm{~mm}^{3}$ is basically designed as a "wind channel" with fins inside and an additional fan mounted to blow along the channel. The stock axial fan was replaced by a high-performance axial fan (Delta Electronics, model AUC0512DB-AF00). Thermal paste was applied between the heater, PHP and heat sink. The other properties of the setup (heater, etc.) are analogous to the setup used for water cooling as shown in Figure 2. 


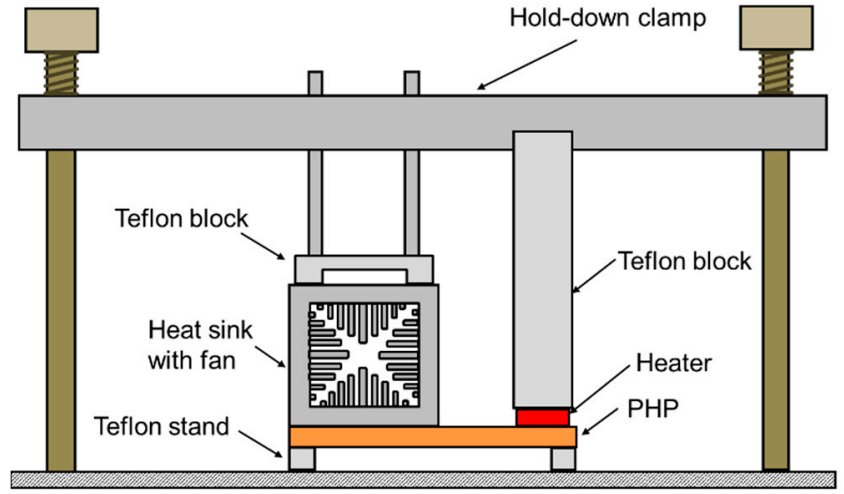

(a)

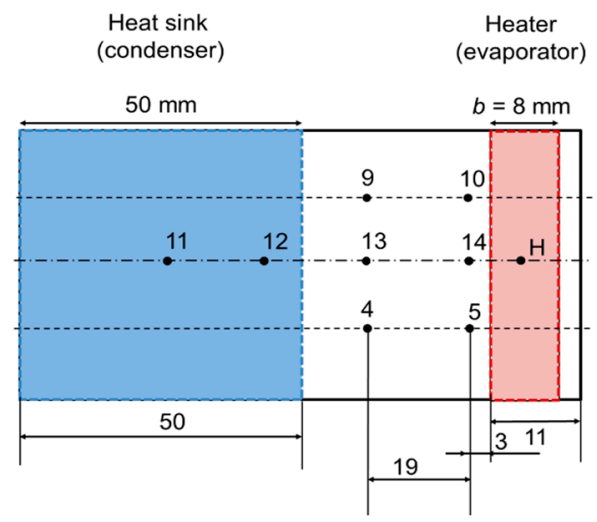

(b)

Figure 3. Measurement setup used for the characterization of the PHP with air cooling (i.e., an air-cooled heat sink). (a) Test bench, (b) positions of thermocouples for measurement setup with air cooling. Thermocouples 4, 5, 9 and 10 are arranged on the top side of the PHP and 11-14 are arranged on one line at the bottom side. $\mathrm{H}$ represents the thermocouple directly inserted into the heater.

The location of the thermocouples is shown in Figure 3. The enumeration of the thermocouples with respect to their position is analogous to Figure 2. The whole setup was isolated by rock wool (ROCKWOOL 800). In the plots of $R_{t h}$ and $T_{H}$ shown in Section 3.3., reference values of an analogous copper plate as measured with the same setup are also given. Since, in the case of the copper plate, there was hardly any scattering in $R_{t h}$ for all applied heat powers, we represent these values as a line giving the average $R_{t h}$.

\section{Results and Discussion}

\subsection{Results Overview}

In this work, two different types of PHPs were analyzed:

1. A PHP with a channel size of $1.5 \times 1.5 \mathrm{~mm}^{2}$ and dimensions of $50 \times 100 \times 2.5 \mathrm{~mm}^{3}$;

2. A PHP with a channel size of $1 \times 1 \mathrm{~mm}^{2}$ and dimensions of $50 \times 100 \times 2.0 \mathrm{~mm}^{3}$.

On overview of the experiments that were carried out in this work and the respective experimental objective is given in Table 1 The majority of the tests were carried out with water cooling.

Table 1. Overview of experiments and objectives.

\begin{tabular}{cccccc}
\hline Section & Cooling & $\begin{array}{c}\text { Channel Size } \\
{[\mathbf{m m} \times \mathbf{m m}]}\end{array}$ & $\mathbf{b}^{\mathbf{1}}[\mathbf{m m}]$ & $\mathbf{L}^{2}[\mathbf{m m}]$ & Objective of Experiment \\
\hline 3.2.1., 3.2.2. & Water & $\begin{array}{c}1 \times 1 \\
1.5 \times 1.5\end{array}$ & 8 & 14 & $\begin{array}{c}\text { Performance test with water } \\
\text { cooling (PHP thermal resistance } \\
\text { and heater temperature) }\end{array}$ \\
\hline 3.2.3. & Water & $1.5 \times 1.5$ & 25 & $10-50$ & $\begin{array}{c}\text { Analysis of effect of condenser } \\
\text { plate width on PHP performance }\end{array}$ \\
\hline 3.2.4. & Water & $1.5 \times 1.5$ & 8 & $10-40$ & $\begin{array}{c}\text { Capability of PHPs to spread heat } \\
\text { from small parts (i.e., evaporator } \\
\text { areas) to significantly larger } \\
\text { condenser areas }\end{array}$ \\
\hline 3.3.1., 3.3.2. & Air & $1.5 \times 1.5$ & 8 & 14 & $\begin{array}{c}\text { Performance test with air cooling } \\
\text { (PHP thermal resistance and } \\
\text { heater temperature) }\end{array}$ \\
\hline
\end{tabular}

${ }^{1}$ Evaporator width (heater width); ${ }^{2}$ condenser width.

\subsection{Results Obtained for Water Cooling}

The results shown here were obtained using the setup shown in Section 2.2.1., Figure 2. 


\subsubsection{PHPs with Channel Size of $1 \times 1 \mathrm{~mm}^{2}$}

Figure 4 shows the results obtained for the PHP with a channel size of $1 \times 1 \mathrm{~mm}^{2}$, a heater width of $8 \mathrm{~mm}$ and a condenser plate width of $14 \mathrm{~mm}$. Excellent thermal properties were achieved for horizontal and vertical orientation despite the small overall dimension of the PHP. For heating powers larger than $130 \mathrm{~W}$, a reduction in $R_{t h}$ of ca. $80 \%$ compared to a solid copper plate with the same dimensions was found. In other words, the effective thermal conductivity of the PHP can be considered to be roughly five times larger than that of a solid copper plate. The minimum power to start the pulsating mode of the PHP was $25 \mathrm{~W}$ for horizontal orientation. For vertical orientation with the heater below the condenser, the PHP was working well already, with a heating power of $8 \mathrm{~W}$. Up to the maximum heating power of ca. $200 \mathrm{~W}$ used in the experiment (corresponding to a heat power density of 50 $\mathrm{W} / \mathrm{cm}^{2}$ ), the stable performance of the PHP was observed.

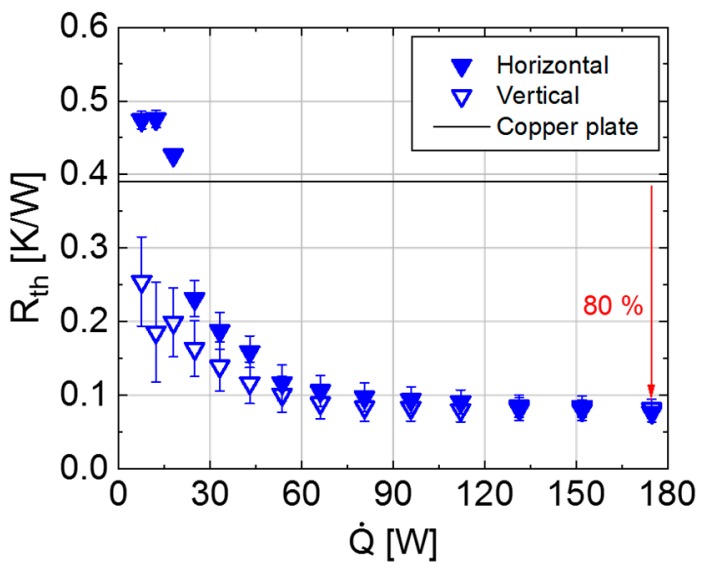

(a)

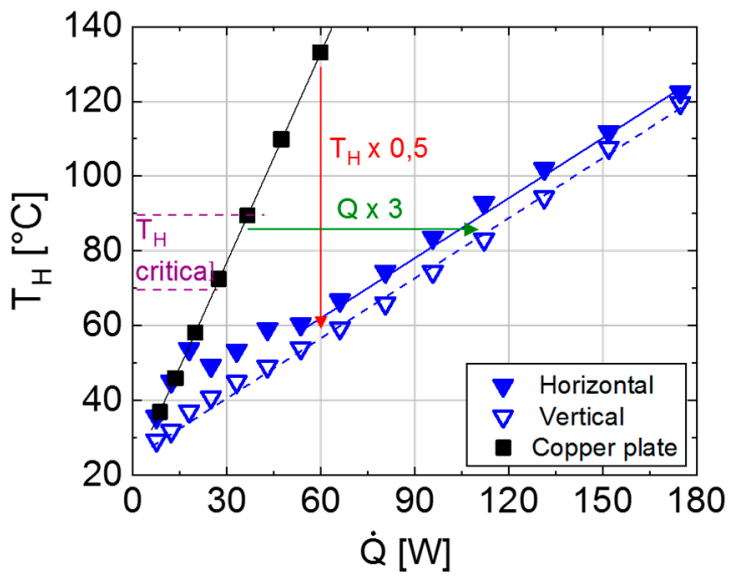

(b)

Figure 4. Results for PHPs with channel size of $1 \times 1 \mathrm{~mm}^{2}$ with water cooling for horizontal and vertical orientation, compared to a solid analogous copper plate (i.e., with the same dimensions) for heating powers up to $180 \mathrm{~W}$. (a) Plot of thermal resistance $R_{t h}$ vs. heating power $Q$. Red arrow: reduction in $R_{t h}$ compared to copper plate; (b) plot of heater temperature $T_{H}$ vs. heating power $Q$. Red arrow: heater temperature of heater on PHP relative to copper plate at the same heating power. Red number: ratio of $\mathrm{T}_{H}$ on PHP vs. copper plate in ${ }^{\circ} \mathrm{C}$. Green arrow: heating power of heater on PHP relative to copper plate at the same temperature of ca. $80-90^{\circ} \mathrm{C}$, which is a critical temperature not to be exceeded for many electronic parts. Green number: ratio of allowed power on PHP vs. copper plate for "critical temperature".

In Figure 4, the heater temperature $T_{H}$ is shown as a function of the heating power when placed on a PHP and on a solid copper plate, respectively. For a heating power of ca. $60 \mathrm{~W}$, the heater reached $133^{\circ} \mathrm{C}$ on the copper plate, but only $60^{\circ} \mathrm{C}$ on the PHP in vertical orientation and $65^{\circ} \mathrm{C}$ in a horizontal orientation, which is less than half the temperature when given in ${ }^{\circ} \mathrm{C}$. One can also consider the temperature difference of the heater to ambient, i.e., cooling, water temperature (ca. $21^{\circ} \mathrm{C}$ ). For a heating power of $60 \mathrm{~W}$, this temperature difference is about $110 \mathrm{~K}$ for a copper plate, but only ca. $40 \mathrm{~K}$ for a PHP, which is a factor of 2.8 lower. We note that this reduction in heater temperature difference $(\sim 64 \%)$ is smaller than the reduction in the PHP's thermal resistance $(\sim 80 \%)$. The reason for this is that in the full thermal path from heater to cooler that results in a certain $T_{H}$, other thermal resistances such as interface thermal resistance between the different parts also play a role. These resistances are nominally equal when a PHP and copper plate are used.

To avoid any pressure-induced leaks in the PHP due to a high vapor pressure of the used fluid Acetone at elevated temperatures, $T_{H}$ was limited to $120^{\circ} \mathrm{C}$ in this experiment. However, the quasi-linear relation between $T_{H}$ and $Q$ (a linear fit with the base function $y=a+b \cdot x$ yielded $\mathrm{a}=$ 20.0 and $b=1.91$ ) allows us to extrapolate that $T_{H}$ would reach as much as $354^{\circ} \mathrm{C}$ for a maximum 
$\mathcal{Q}$ of $175 \mathrm{~W}$ on a copper plate, whereas it is only ca. $120{ }^{\circ} \mathrm{C}$ on a PHP at this heating power. This demonstrates how the thermal advantage of a PHP increases with increasing heating powers. It should be emphasized that the limits of the PHP concerning maximum heating power and temperature were not fully tested out in these experiments, since the heater temperature was limited to $120{ }^{\circ} \mathrm{C}$. The maximum heating power can be increased by increasing heater and condenser plate width, as shown below in Section 3.2.3.

\subsubsection{PHPs with Channel Size of $1.5 \times 1.5 \mathrm{~mm}^{2}$}

Figure 5 shows the results obtained for the PHP with a channel size of $1.5 \times 1.5 \mathrm{~mm}^{2}$, a heater width of $8 \mathrm{~mm}$ and a condenser plate width of $14 \mathrm{~mm}$. From previous studies (e.g., [10,15]), it was expected that increasing the channel size should lower the flow resistance of the pulsating fluid plugs and thus result in a higher heat throughput capacity. Indeed, at a heating power of $150 \mathrm{~W}$, the reduction in $R_{t h}$ relative to an analogous copper plate was, at $83 \%$, even higher than for the PHP with $1 \times 1 \mathrm{~mm}^{2}$ channels. This corresponds to the effective thermal conductivity of the PHP being roughly six times higher than that of a solid copper plate, i.e., about as high as natural diamond (2400-2500 W/mK [17]). However, in horizontal orientation, reproducible dryout phenomena were observed. When increasing the heat power from 115 to $130 \mathrm{~W}$, the typical small temperature fluctuations associated with PHP operation (e.g., due to liquid plug movement) ceased suddenly and the heater temperature increased abruptly (Figure 6). The measurement was quickly aborted at this point due to the heater exceeding the preset maximum safe temperature of $140{ }^{\circ} \mathrm{C}$ and no further data for $R_{t h}$ and $T_{H}$ was acquired. In contrast to this, as shown above, no dryout phenomena were observed on the PHP with $1 \times 1 \mathrm{~mm}^{2}$ channels. The higher stability of PHP activity in the small-channel PHP for high heat powers is in good agreement with previous reports in the literature [10,14], as outlined in Section 2.1. For horizontal orientation, taking care to ensure a high PHP activity (bubble growth, collapse, fluid exchange between evaporator and condenser, etc.) and prevent dryout is even more important than for vertical orientation, since there are no gravitational forces present that enhance liquid transport back to the condenser. Similar to the observations in this work, there are several reports in the literature in which PHPs worked well in vertical orientation, but had a significant loss of heat transport capability in horizontal orientation, see, e.g., [15,18,19].

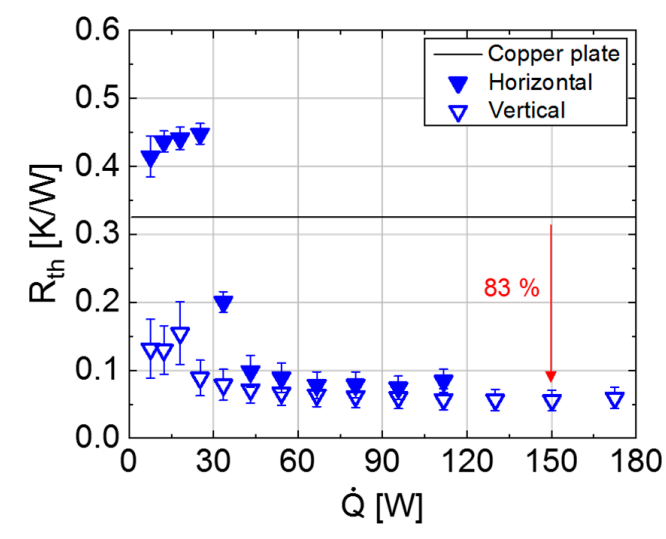

(a)

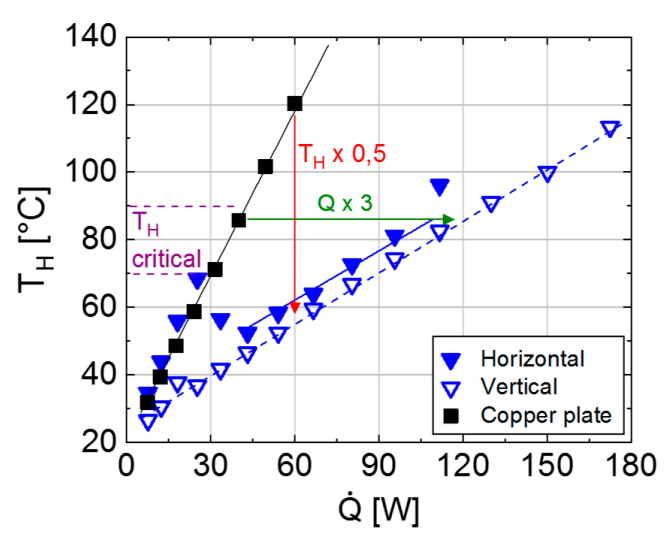

(b)

Figure 5. Results for PHPs with channel size of $1.5 \times 1.5 \mathrm{~mm}^{2}$ with water cooling for horizontal and vertical orientation for heating powers up to $180 \mathrm{~W}$, compared to a solid analogous copper plate. (a) Plot of thermal resistance $R_{t h}$ vs. heating power $Q$. Red arrow: reduction in $R_{t h}$ compared to copper plate; (b) plot of heater temperature $T_{H}$ vs. heating power $Q$. Red arrow: heater temperature of heater on PHP relative to copper plate at the same heating power. Green arrow: heating power of heater on PHP relative to copper plate at the same temperature of ca. $80-90^{\circ} \mathrm{C}$, which is a critical temperature not to be exceeded for many electronic parts. 


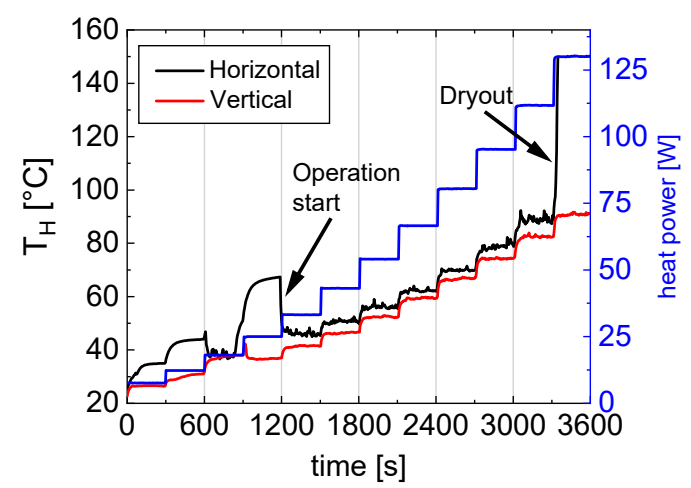

Figure 6. PHP with $1.5 \times 1.5 \mathrm{~mm}^{2}$ channels. Plot of heater temperature $T_{H}$ and heating power $Q$ vs. time for horizontal orientation. The PHP started operating reliably only at a heating power of 30-40 $\mathrm{W}$. For a heating power $>115 \mathrm{~W}$, dryout occurred in horizontal orientation with heater temperature increasing abruptly.

With 30-40 W, the required startup power in horizontal orientation was slightly higher than for the PHP with $1 \times 1 \mathrm{~mm}^{2}$ channels. For vertical orientation with the heater below the condenser, already at $8 \mathrm{~W}$ (which is the lowest heating power step) the PHP was operating well. Moreover, for this PHP, we did not test out maximum heating power and temperature since the heater temperature was limited to $120^{\circ} \mathrm{C}$. The maximum heating power can be increased (and dryout avoided) by increasing heater and condenser plate width, as shown below in Section 3.2.3.

\subsubsection{Effect of Condenser Plate Width on PHP Properties}

As described in Section 3.2.2., the PHP with channel size of $1.5 \times 1.5 \mathrm{~mm}^{2}$ ceased operation above $115 \mathrm{~W}$ due to dryout condition when using a heater width of $8 \mathrm{~mm}$ and a condenser plate width $L$ of 14 $\mathrm{mm}$. It is expected that increasing the condenser area should decrease dryout probability since there is a larger area available for condensation processes, increasing the probability of liquid formation. As shown in Figure 7, these assumptions were confirmed experimentally. For the shown tests, a heater with a width of $25 \mathrm{~mm}$ was used.

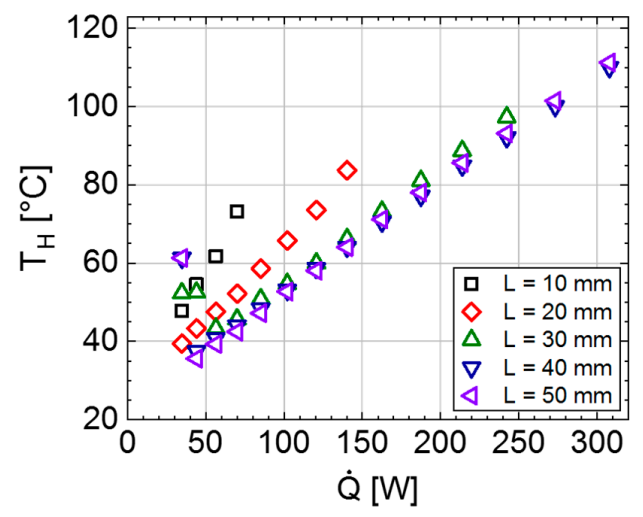

(a)

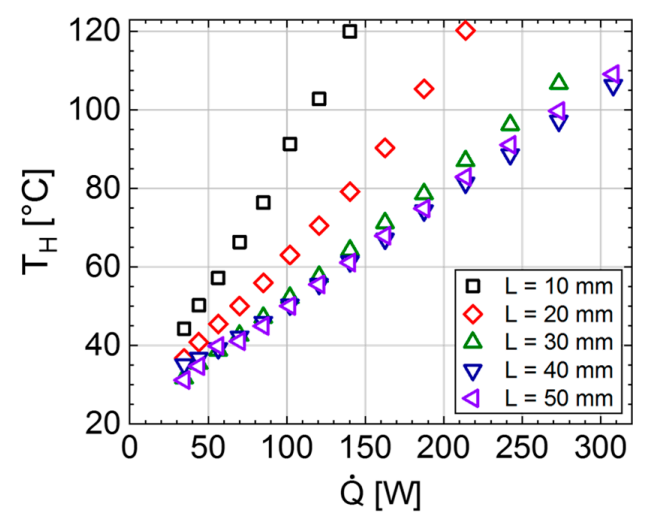

(b)

Figure 7. Plot of heater temperature $T_{H}$ vs. heating power $Q$ for a heater width of $25 \mathrm{~mm}$ and condenser plate widths $L$ of $10-50 \mathrm{~mm}$ for PHP with channel size of $1.5 \times 1.5 \mathrm{~mm}^{2}$. (a) horizontal orientation; (b) vertical orientation.

In horizontal orientation, increasing the condenser plate width delayed the occurrence of dryout. At $L=10-30 \mathrm{~mm}$, the measurements had to be aborted above certain heat power levels due to dryout (no further data points given in plot). At $L=40-50 \mathrm{~mm}$, no dryout occurred at all up to heating powers of as much as $300 \mathrm{~W}$ and the PHP was working in a similar way to the vertical orientation. 
Moreover, in vertical orientation, the increased heater and condenser plate width had beneficial effects. For $L=20$ and $30 \mathrm{~mm}$, dryout was observed for powers exceeding 215 and $274 \mathrm{~W}$, respectively. For $L=40-50 \mathrm{~mm}$, no dryout was observed in the full power range up to $300 \mathrm{~W}$.

Analogous data for the reference copper plate is given in Figure 8. Combining the data of the PHP and copper plate allows us to draw more conclusions. In Figure $9 \mathrm{a}$, a comparison of heater temperature $T_{H}$ vs. heating power $Q$ is given between a PHP and reference copper plate for a fixed condenser plate width of $30 \mathrm{~mm}$. For a heating power of $129 \mathrm{~W}$, the heater reached $173^{\circ} \mathrm{C}$ on the copper plate, but only $61{ }^{\circ} \mathrm{C}$ on the PHP. To reach a temperature of around $90{ }^{\circ} \mathrm{C}$ (which is a critical temperature for many electronic parts) on a copper plate only $58 \mathrm{~W}$ is required or allowed, while the same temperature is reached on a PHP at a power of ca. $214 \mathrm{~W}$, which is an increase by a factor of 3.7. When comparing this to the analogous data given in Figure 5 (smaller heater width of $8 \mathrm{~mm}$ and condenser plate width of 14 $\mathrm{mm}$ ), the advantage of a PHP compared to solid copper is even more evident.

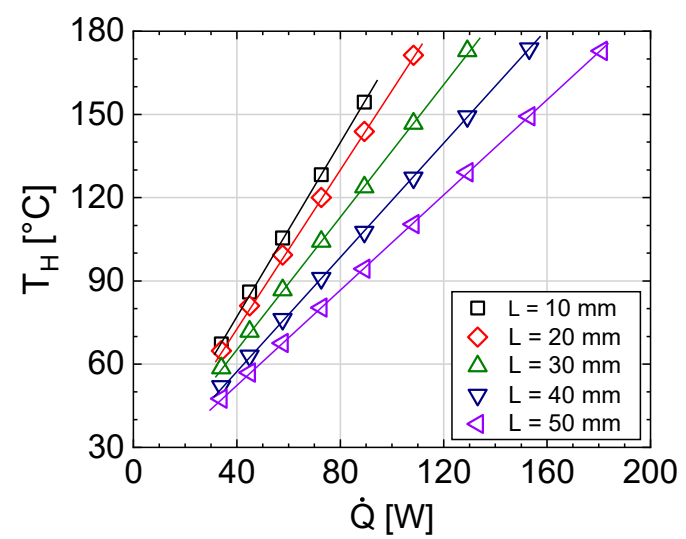

Figure 8. Plot of heater temperature $T_{H}$ vs. heating power $Q$ for condenser plate widths of $10-50 \mathrm{~mm}$ for reference copper plate. Lines are given as eye guides.

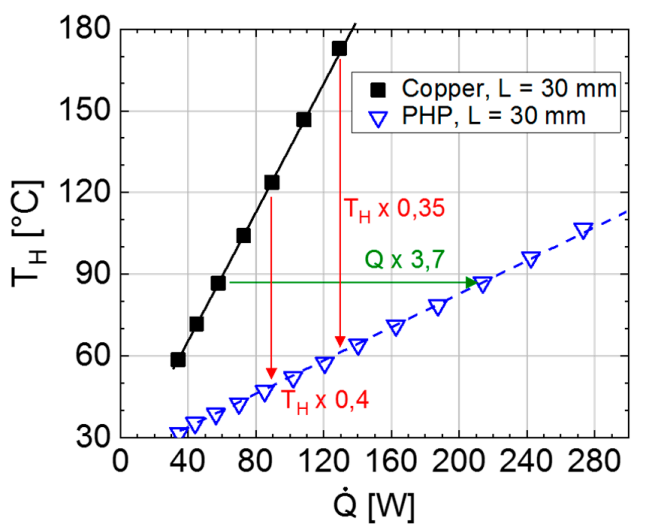

(a)

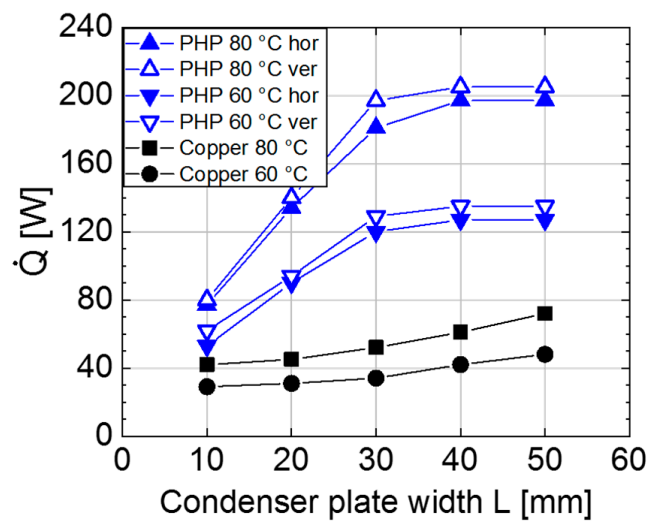

(b)

Figure 9. (a) Comparison of heater temperature $T_{H}$ vs. heating power $Q$ between PHP (vertical orientation) and reference copper plate for fixed condenser plate width of $30 \mathrm{~mm}$ and a heater width of $25 \mathrm{~mm}$. Lines are given as eye guides; (b) plot of $Q$ for defined $T_{H}$ of 60 and $80^{\circ} \mathrm{C}$ vs. $L$ for PHP (blue triangles) and reference copper plate (black squares and circles). Hor $=$ horizontal orientation. Ver $=$ vertical orientation. For the copper plate, the values for horizontal and vertical orientation are identical and thus, only one value is given for each.

The obtained data also allows us to plot the allowable heating power when a certain heater temperature of 60 and $80^{\circ} \mathrm{C}$ is given. For the same condenser plate width, this allowable power is much higher for a PHP, as shown in Figure 9b. The data for this plot was extracted from Figures 7 
and 8. Altogether, the obtained results highlight the importance of choosing an appropriately sized condenser area.

\subsubsection{Heat Spreading Capability of PHPs with Channel Size of $1.5 \times 1.5 \mathrm{~mm}^{2}$}

The ability of the PHP with a channel size of $1.5 \times 1.5 \mathrm{~mm}^{2}$ to "spread heat" for different heater widths was analyzed. Here, we consider the heat spreading capability as the ability to distribute the heat generated by a small heat source (i.e., heater) with width $b$ to a condenser zone or condenser plates with significantly larger width $L$. A low thermal conductivity of the heat conducting object should result in low heat spreading capabilities, i.e., a "thermal current crowding" at the edge of the condenser plate facing the heater (Figure 10) and the inability to exploit the whole condenser area for thermal transport. In contrast, a high thermal conductivity should allow the exploitation of the condenser area almost fully for thermal conduction and thus allow us to dissipate larger heat flows at the same heater temperature level.

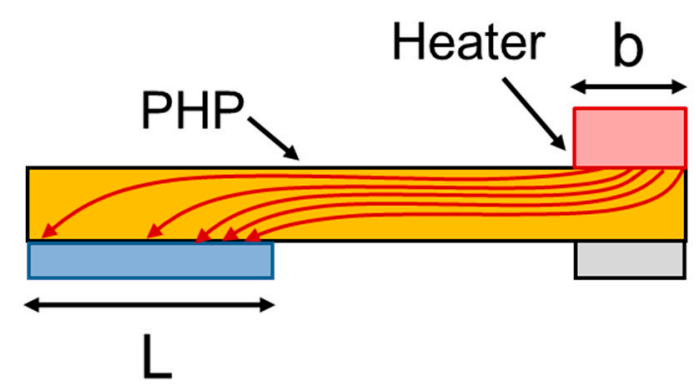

Figure 10. Schematic illustration of heat flow (red lines) in a PHP with a heater (width b) and a condenser plate (width $L$ ).

In fact, it was shown that the thermal energy generated from a small heater with a width of $8 \mathrm{~mm}$ can be spread to much larger condenser areas with widths of 14,30 and $40 \mathrm{~mm}$. A nearly linear relationship between the applicable heating power at the same heater temperature and the condenser plate width was observed (Figure 11). This means that the PHP also works well with large condenser areas, allowing us to spread the heat from a small hot part to areas that are up to five times as large. The stagnation of the applicable heating power for an increasing condenser width that would have indicated the stagnation of the heat spreading capability was not observed in this experiment (condenser plate widths of up to $40 \mathrm{~mm}$ ).

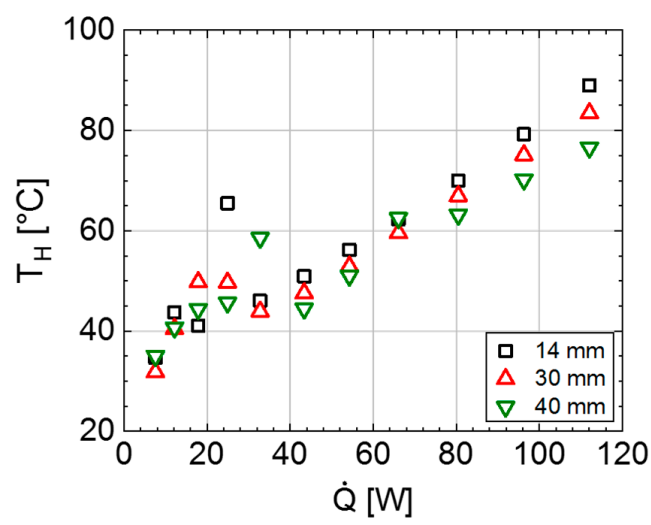

(a)

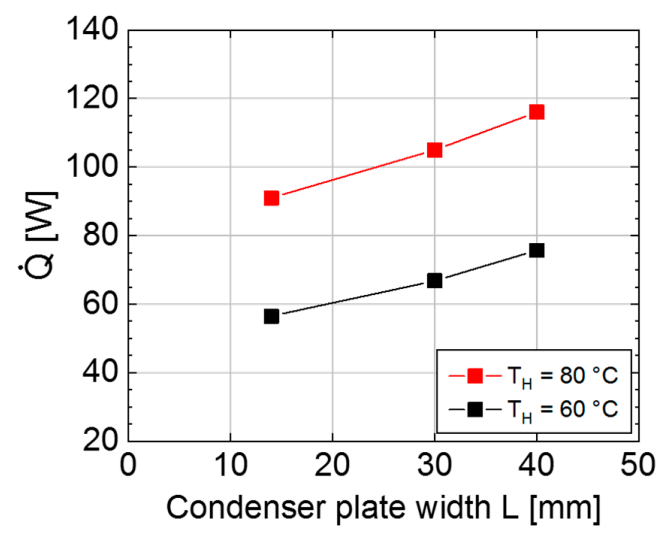

(b)

Figure 11. Heat spreading experiments on PHP with $1.5 \times 1.5 \mathrm{~mm}^{2}$ channels in horizontal orientation. (a) Plot of heater temperature $T_{H}$ vs. heating power $Q$ for condenser plate widths of 14,30 and $40 \mathrm{~mm}$;

(b) "Isothermal" plots of $Q$ vs. condenser plate width $L$ for fixed $T_{H}$. Data obtained from left plot. 


\subsubsection{Comparison to the Literature Data}

In Table 2 the properties and performance metrics of the PHPs characterized in this work are compared to selected results given in the literature. Only results obtained on flat-plate PHPs and boundary conditions comparable to this work are given here, meaning that the following types of published works are not included: PHPs made of bent tubes, PHPs with 3D-channel structures (such as shown in [20]), PHP tests with a heat source that is not at the side of the PHP or with multiple heat sources and PHPs designed for cold side temperatures far away from room temperature (i.e., high-temperature and cryogenic PHPs). Only results achieved with water cooling at the condenser zone are reported. If results for multiple orientations are given, only the results for vertical orientation (heater at the bottom) and horizontal orientation are shown in the table. If results for multiple fill ratios are given, only the best results are shown in the table.

Table 2. Characteristic properties and performance metrics of PHPs from this work, compared to previous results from the literature.

\begin{tabular}{|c|c|c|c|c|c|c|c|c|c|c|c|}
\hline $\begin{array}{l}\text { Total PHP Size }{ }^{1} \\
{[\mathrm{~mm}]}\end{array}$ & $\begin{array}{c}\text { Ch. Size } \\
\text { [mm] }\end{array}$ & \# chs. & $\begin{array}{c}\text { Ch. } \\
\text { Dens. }{ }^{2} \\
{\left[1 / \mathrm{mm}^{2}\right]} \\
\times 10^{3}\end{array}$ & $\begin{array}{l}\text { Container } \\
\text { Material }\end{array}$ & Fluid & $\begin{array}{c}\text { Max. } \\
\text { Test. } \\
\text { Heat Pow. } \\
{ }^{3}[W]\end{array}$ & $\begin{array}{c}\text { Max. } \\
\text { Pow. } \\
\text { Dens. }{ }^{4} \\
{\left[W / \mathrm{cm}^{2}\right]}\end{array}$ & Or. $\mathrm{H} / \mathrm{V}^{5}$ & $\begin{array}{l}\text { Eff. Th. } \\
\text { Cond. } \\
\text { [W/mK] }\end{array}$ & $\begin{array}{l}\text { Ratio } R_{\text {th }} \\
\text { Filled/Dry }\end{array}$ & Ref. \\
\hline $100 \times 50 \times 2.0$ & $1 \times 1$ & 26 & 5.2 & Copper & Acetone & $\begin{array}{l}175^{6} \\
175^{6}\end{array}$ & $\begin{array}{l}44 \\
44\end{array}$ & $\begin{array}{l}\mathrm{H} \\
\mathrm{V}\end{array}$ & $\begin{array}{l}2000 \\
2000\end{array}$ & $\begin{array}{l}<0.20^{7} \\
<0.20^{7}\end{array}$ & t.w. \\
\hline $100 \times 50 \times 2.5$ & $1.5 \times 1.5$ & 20 & 4.0 & Copper & Acetone & $\begin{array}{l}128^{6} \\
175^{6} \\
\end{array}$ & $\begin{array}{l}28 \\
44 \\
\end{array}$ & $\begin{array}{l}\mathrm{H} \\
\mathrm{V}\end{array}$ & $\begin{array}{l}1500 \\
2300\end{array}$ & $\begin{array}{l}<0.26^{7} \\
<0.17^{7}\end{array}$ & t.w. \\
\hline $177 \times 127 \times 3.8$ & $2 \times 2$ & 20 & 0.89 & Aluminum & Water & 100 & 3.8 & $\mathrm{~V}$ & - & 0.25 & [22] \\
\hline $300 \times 300 \times 6$ & $1.3 \times 1.3$ & 40 & 0.44 & Aluminum & Acetone & 500 & 2.2 & $\mathrm{H}$ & - & 0.30 & [11] \\
\hline $132 \times 50 \times 3$ & $2.2 \times 2.0$ & 12 & 1.8 & Aluminum & Methanol & 90 & 13 & $\mathrm{~V}$ & - & 0.13 & [18] \\
\hline $194 \times 101 \times 5$ & $1.2 \times 1.2$ & 34 & 1.7 & Copper & Ethanol & 160 & 6.3 & $\mathrm{~V}$ & - & 0.65 & [12] \\
\hline $180 \times 120 \times 3$ & $1 \times 1$ & 66 & 3.1 & Copper & Ethanol & $\begin{array}{l}190 \\
240\end{array}$ & $\begin{array}{c}6.3 \\
8\end{array}$ & $\begin{array}{l}\mathrm{H} \\
\mathrm{V}\end{array}$ & $\begin{array}{l}- \\
-\end{array}$ & $\begin{array}{l}0.15 \\
0.13\end{array}$ & [10] \\
\hline $180 \times 120 \times 3$ & $2 \times 2$ & 40 & 1.9 & Aluminum & Ethanol & $\begin{array}{l}370 \\
400\end{array}$ & $\begin{array}{l}12 \\
13\end{array}$ & $\begin{array}{l}\mathrm{H} \\
\mathrm{V}\end{array}$ & - & $\begin{array}{l}0.06 \\
0.05\end{array}$ & [10] \\
\hline $88 \times 50 \times 3.5$ & $1 \times 1.5$ & 20 & 4.6 & Copper ${ }^{8}$ & Water & 275 & 28 & $\mathrm{~V}$ & - & - & [21] \\
\hline $50 \times 15.5 \times 1.5$ & $1 \times 0.4$ & 10 & 12.9 & Silicon & Ethanol & $\begin{array}{l}3 \\
4\end{array}$ & $\begin{array}{l}1.3 \\
1.8\end{array}$ & $\begin{array}{l}\mathrm{H} \\
\mathrm{V}\end{array}$ & $\begin{array}{l}300 \\
600\end{array}$ & $\begin{array}{l}0.4 \\
0.2\end{array}$ & [23] \\
\hline
\end{tabular}

Abbreviations in table: channel size (Ch. size), number of channels (\# chs.), channel density (Ch. dens.), maximum tested heat power (Max. test. heat pow.), maximum power density (Max. pow. dens.), orientation horizontal or vertical (Or. H/V), effective thermal conductivity (Eff. th. cond.), reference (Ref.); this work (t.w); ${ }^{1}$ total size (including marginal areas without channels); ${ }^{2}$ number of channels divided by total PHP area; ${ }^{3}$ maximum heat power that was successfully tested (without PHP operation failure due to dryout); ${ }^{4}$ maximum heat power that was successfully tested, divided by heater area (without PHP operation failure due to dryout); ${ }^{5}$ horizontal $(\mathrm{H})$, vertical with bottom heater $(\mathrm{V}) ;^{6}$ results for heater width $=8 \mathrm{~mm}$, condenser width $=14 \mathrm{~mm} ;{ }^{7}$ ratio not directly given in this work. An upper limit for the ratio was estimated from assuming a lower limit for the thermal resistance of the dry PHP by assuming that it has a thermal resistivity corresponding to a body of full copper; ${ }^{8}$ evaporator/condenser section with hydrophilic $\mathrm{CuO}$ nanostructures.

Evidently, there is a trend between channel density (number of channels per total PHP area) and performance. The PHPs with highest channel density as presented in this work and [21] rank among the highest achieved heat power densities. On the other hand, the PHPs with the lowest channel densities ([11,22]) exhibit the lowest achieved heat power densities. A clear exception to this rule is [23] (last table entry), which is the only listed work where microscale channels were used. Here, due to the very low channel dimensions, we suspect that the fluidic resistance increases strongly, leading to a reduction in fluid velocity and thermal transport. Consequently, despite a very high channel density, the achieved maximum heat power densities are comparably low.

In conclusion, it appears that a high channel density is favorable for PHP performance, but only as long as the channel size does not become too small. In this context, we note that the diameter threshold under which the PHP performance deteriorates strongly depends on several properties and no detailed study has been carried out yet [9]. It is also difficult to analyze this problem by simulation, as the PHP functioning is not completely understood from a theoretical point of view; tools for the 
PHP dimensioning are still absent, even today, and the modeling of PHPs is generally considered very difficult due to the multitude of complex fluidic and two-phase thermal processes interacting $[9,24]$.

\subsection{Results Obtained for Air Cooling}

Due to less complexity and cost, air-based cooling systems are preferred over water-based systems in many applications. Therefore, the PHPs were also tested with an air-cooled heat sink with a footprint of $50 \times 50 \mathrm{~mm}^{2}$ at the condenser section. Details on the used setup are given in Section 2.2.2., Figure 3 .

\subsubsection{PHPs with Channel Size of $1 \times 1 \mathrm{~mm}^{2}$}

With air cooling at the condenser zone, the examined PHP also exhibited a significantly better thermal transport compared to a conventional copper plate in horizontal and vertical orientation (Figure 12). The reduction in $R_{t h}$ was similar to water cooling. The reduction in $T_{H}$ compared to a copper plate and the increase in $Q$ at a given "critical" temperature around $80-90{ }^{\circ} \mathrm{C}$ was not as pronounced as for water cooling. The reason for this is that the adiabatic section of the PHP (i.e., the area between evaporator and condenser area) is much smaller in the case of air cooling (see Figures 2 and 3). This means that in the full thermal path from heater to cooler that determines $T_{H}$, the thermal resistance of the PHP plays a less significant role in relation to other thermal resistances in the setup. Thus, a reduction in $R_{t h}$ of only the PHP influences $T_{H}$ to a lesser degree.

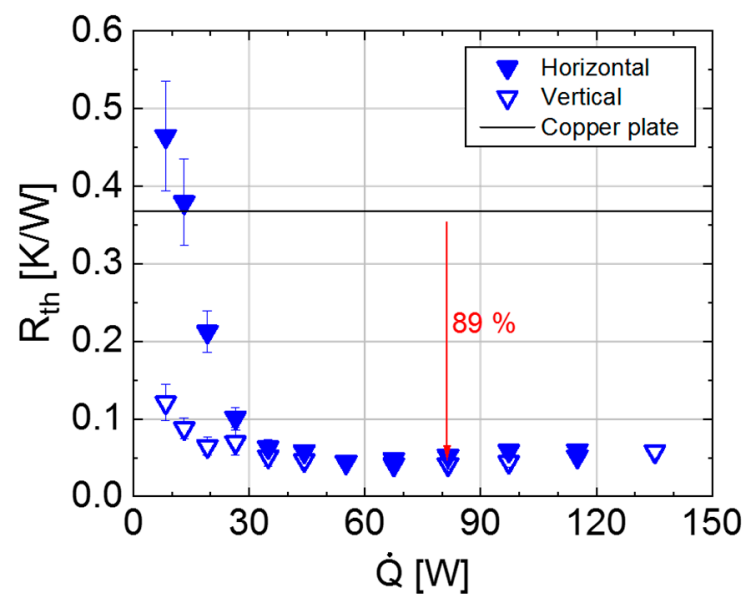

(a)

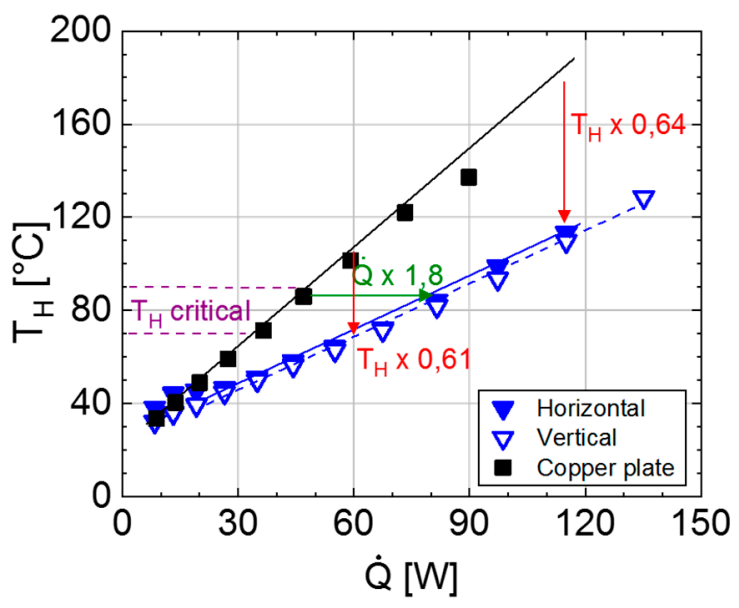

(b)

Figure 12. Results for PHPs with channel size of $1 \times 1 \mathrm{~mm}^{2}$ with air cooled heat sink, compared to a solid analogous copper plate. (a) Plot of thermal resistance $R_{t h}$ vs. heating power $Q$. Red arrow: reduction in $R_{t h}$ compared to copper plate; $(\mathbf{b})$ plot of heater temperature $T_{H}$ vs. heating power $Q$. Results for horizontal and vertical orientation of the PHP with respect to gravity are given. Red arrow: heater temperature of heater on PHP relative to copper plate at the same heating power. Green arrow: heating power of heater on PHP relative to copper plate at the same temperature.

\subsubsection{PHPs with Channel Size of $1.5 \times 1.5 \mathrm{~mm}^{2}$}

The behavior of the air-cooled PHP with respect to channel size was comparable to water cooling (Figure 13). However, with the applied heating powers, it was not possible to sustain a continuous PHP operation in horizontal orientation. The suspected reason is that fluid recondensation at the condenser area was not as efficient as for water cooling, since air cooling is known to transfer heat (and also latent heat) less effectively than water cooling. Thus, an insufficient amount of liquid was available at the evaporator. Consequently, heat was almost exclusively transported by direct heat conduction through the copper container material. The resulting $R_{t h}$ was higher than that of an analogous full copper plate since the PHP contained a large proportion of cavities (i.e., fluid channels). This trend of reduced operation in horizontal orientation was already observed for water cooling (Section 3.2.2., later startup 
and dryout problems). In contrast to this, the PHP was operating well in vertical orientation already at the lowest applied heating power of $8 \mathrm{~W}$.

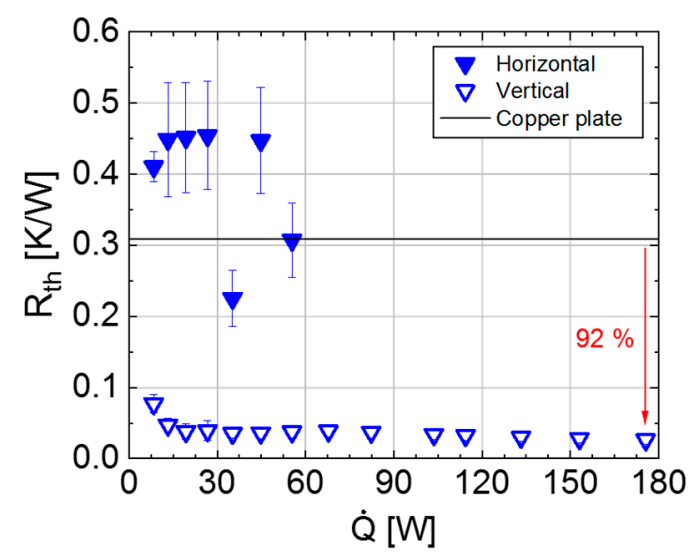

(a)

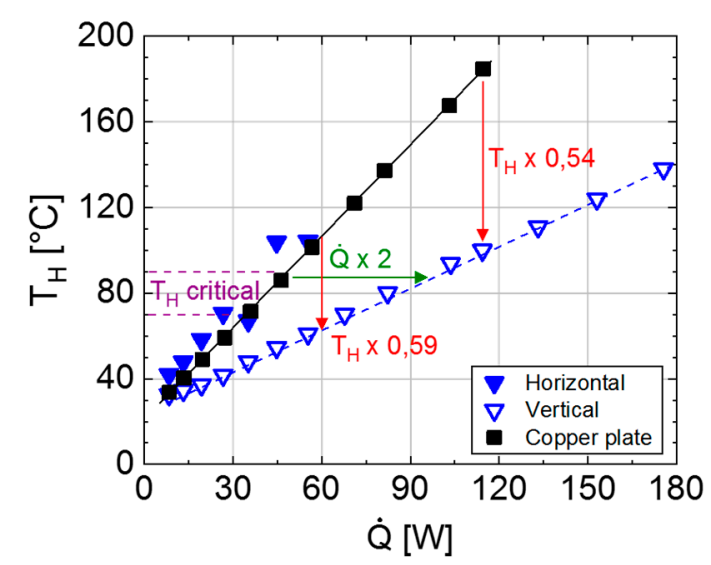

(b)

Figure 13. Results for PHPs with channel size of $1.5 \times 1.5 \mathrm{~mm}^{2}$ with air cooled heat sink, compared to a solid analogous copper plate. (a) Plot of thermal resistance $R_{t h}$ vs. heating power $Q$. Red arrow: reduction in $R_{t h}$ compared to copper plate; (b) plot of heater temperature $T_{H}$ vs. heating power $Q$. Results for horizontal and vertical orientation of the PHP with respect to gravity are given. Red arrows: heater temperature of heater on PHP relative to copper plate at the same heating power. Green arrow: heating power of heater on PHP relative to copper plate at the same temperature.

\section{Conclusions}

The scope of this work was the analysis of small and compact PHPs with respect to practical applications and optimization for electronics cooling with high power densities.

According to the literature, both a high fluid channel density and a sufficient channel size are key to achieving a high thermal performance. Consequently, the PHPs in this work were optimized with these aspects in mind, resulting in excellent thermal properties. Depending on input heating power, the thermal resistance was found to be much (ca. $80 \%-90 \%$ ) smaller than that of an analogous solid copper plate with the same dimensions. Consequently, a hot part with defined thermal heat loss would remain at a much lower temperature level compared to a copper plate. Exemplarily, for a heater zone width of $25 \mathrm{~mm}$, a condenser zone width of $30 \mathrm{~mm}$ and a heating power of ca. $130 \mathrm{~W}$, the heater temperature reached ca. $170{ }^{\circ} \mathrm{C}$ on a copper plate, but only ca. $60^{\circ} \mathrm{C}$ on a PHP with the same dimensions.The PHPs were found to work well with air cooling, water cooling, in vertical and horizontal orientation (depending on experimental parameters) and also exhibited a good heat-spreading capability. The condenser area size was found to significantly influence the operation and performance of PHPs. PHPs with larger channels $\left(1.5 \times 1.5 \mathrm{~mm}^{2}\right.$ vs. $\left.1.0 \times 1.0 \mathrm{~mm}^{2}\right)$ show a smaller thermal resistance and higher heat transport capability at high heating powers compared to a reference copper plate, but were more susceptible to dryout condition in horizontal orientation (depending on heater and condenser plate width).

In conclusion, in this work, we were able to identify several factors that contribute to a high PHP performance:

- High fluid channel density;

- Proper channel size, also with respect to boundary conditions such as PHP orientation;

- Proper sizing of heater and condenser area.

In our opinion, the next steps to be addressed in the future are:

- The interplay of PHP performance metrics with fluid channel density, channel size, filling ratio, working fluid, heater/condenser size and position, etc. Therefore, as a long-term goal, simulation 
and proper dimensioning of PHPs are envisioned by us in order to be able to find the proper parameters in a more straightforward manner without the need for extensive prototyping;

- Tests on the stability of the PHPs against aging and temperature effects;

- Investigation of the performance limit of the PHPs with regard to maximum heat load;

- Integration of PHPs in actual electrical systems with components with high thermal loads to be cooled.

As a further outlook for the shown PHPs, we are also envisioning the possibility of "thermal switching", meaning that the thermal resistance can be adjusted and adapted by modifying the fluid channels. For example, it was shown that hydrophobic or hydrophilic inner channel surfaces significantly influence PHP heat transport capability $[25,26]$. Another approach to tune the PHPs' thermal resistance could be to integrate functional materials that affect the inner channel structure upon the influence of an externally applied fields or at a certain temperature.

Author Contributions: Conceptualization, M.W., K.B., E.W. and J.C.; methodology, M.W., A.M., F.Z., M.V. and D.R.; investigation, M.W., A.M., D.R., F.Z.; writing—original draft preparation, M.W.; writing—review \& editing, K.B., O.S.-W., E.W. and J.C.; visualization, M.W. and D.R.; supervision, K.B. and O.S.-W.; project administration, M.W.; funding acquisition, M.W. and K.B. All authors have read and agreed to the published version of the manuscript.

Funding: This work was funded by internal funding of the Fraunhofer Society, Munich (i) by the funding program MEF (Mittelstandsorientierte Eigenforschung) for developing applications for small to medium enterprises and (ii) by the Fraunhofer Cluster of Excellence Programmable Materials.

Conflicts of Interest: The authors declare no conflict of interest.

\section{References}

1. Ma, H. Oscillating Heat Pipes; Springer: New York, NY, USA, 2015; ISBN 978-1-4939-2503-2.

2. Zhang, Y.; Faghri, A. Advances and unsolved issues in pulsating heat pipes. Heat Transf. Eng. 2008, $29,20-44$. [CrossRef]

3. Taft, B.S.; Williams, A.D.; Drolen, B.L. Review of pulsating heat pipe working fluid selection. J. Thermophys. Heat Transf. 2012, 26, 651-656. [CrossRef]

4. Khandekar, S.; Charoensawan, P.; Groll, M.; Terdtoon, P. Closed loop pulsating heat pipes Part B: Visualization and semi-empirical modeling. Appl. Therm. Eng. 2003, 23, 2021-2033. [CrossRef]

5. Holley, B.; Faghri, A. Analysis of pulsating heat pipe with capillary wick and varying channel diameter. Int. J. Heat Mass Transf. 2005, 48, 2635-2651. [CrossRef]

6. Kwon, G.H.; Kim, S.J. Operational characteristics of pulsating heat pipes with a dual-diameter tube. Int. J. Heat Mass Transf. 2014, 75, 184-195. [CrossRef]

7. Thompson, S.M.; Ma, H.B.; Wilson, C. Investigation of a flat-plate oscillating heat pipe with Tesla-type check valves. Exp. Therm. Fluid Sci. 2011, 35, 1265-1273. [CrossRef]

8. Patel, V.M.; Gaurav; Mehta, H.B. Influence of working fluids on startup mechanism and thermal performance of a closed loop pulsating heat pipe. Appl. Therm. Eng. 2017, 110, 1568-1577. [CrossRef]

9. Marengo, M.; Nikolayev, V.S. Chapter 1: Pulsating heat pipes: Experimental analysis, design and application. In Encyclopedia of Two-Phase Heat Transfer and Flow IV: Modeling Methodologies, Boiling of $\mathrm{CO}_{2}$, and Micro-Two-Phase Cooling; Thome, J.R., Ed.; World Scientific: Singapore, 2018; pp. 1-62.

10. Yang, H.; Khandekar, S.; Groll, M. Performance characteristics of pulsating heat pipes as integral thermal spreaders. Int. J. Therm. Sci. 2009, 48, 815-824. [CrossRef]

11. Taft, B.S. Non-Condensable gases and oscillating heat pipe operation. Front. Heat Pipes 2013, 4. [CrossRef]

12. Takawale, A.; Abraham, S.; Sielaff, A.; Mahapatra, P.S.; Pattamatta, A.; Stephan, P. A comparative study of flow regimes and thermal performance between flat plate pulsating heat pipe and capillary tube pulsating heat pipe. Appl. Therm. Eng. 2019, 149, 613-624. [CrossRef]

13. Laun, F.F.; Lu, H.; Ma, H.B. An experimental investigation of an oscillating heat pipe heat spreader. J. Therm. Sci. Eng. Appl. 2015, 7. [CrossRef]

14. Borkar, R.S.; Pachghare, P.R. Effect of working fluid, filling ratio and number of turns on pulsating heat pipe thermal performance. Front. Heat Pipes 2015, 6. [CrossRef] 
15. Charoensawan, P.; Khandekar, S.; Groll, M.; Terdtoon, P. Closed loop pulsating heat pipes Part A: Parametric experimental investigations. Appl. Therm. Eng. 2003, 23, 2009-2020. [CrossRef]

16. Senjaya, R.; Inoue, T. Oscillating heat pipe simulation considering dryout phenomena. Heat Mass Transf. 2014, 50, 1429-1441. [CrossRef]

17. Pan, L.S.; Kania, D.R. (Eds.) Diamond: Electronic Properties and Applications; Springer: Boston, MA, USA, 1995; ISBN 978-0-7923-9524-9.

18. Srikrishna, P.; Siddharth, N.; Reddy, S.U.M.; Narasimham, G.S.V.L. Experimental investigation of flat plate closed loop pulsating heat pipe. Heat Mass Transf. 2019, 29, 20. [CrossRef]

19. Wits, W.W.; Groeneveld, G.; van Gerner, H.J. Experimental investigation of a flat-plate closed-loop pulsating heat. In Proceedings of the Joint 19th IHPC and 13th IHPS, Pisa, Italy, 10-14 June 2018.

20. Thompson, S.M.; Ma, H.B. Effect of localized heating on three-dimensional flat-plate oscillating heat pipe. Adv. Mech. Eng. 2010, 2, 465153. [CrossRef]

21. Zhang, F.Z.; Winholtz, R.A.; Black, W.J.; Wilson, M.R.; Taub, H.; Ma, H.B. Effect of hydrophilic nanostructured cupric oxide surfaces on the heat transport capability of a flat-plate oscillating heat pipe. J. Heat Transf. 2016, 138. [CrossRef]

22. Hoesing, M. Integration of a pulsating heat pipe in a flat plate heat sink. J. Undergrad. Res. 2014, 12, $21-36$.

23. Youn, Y.J.; Kim, S.J. Fabrication and evaluation of a slicon-based micro pulsating heat spreader. Sens. Actuators A Phys. 2012, 174, 189-197. [CrossRef]

24. Nekrashevych, I.; Nikolayev, V.S. Pulsating heat pipe simulations: Impact of PHP orientation. Microgravity Sci. Technol. 2019, 31, 241-248. [CrossRef]

25. Betancur, L. (Ed.) Experimental study of start-up in a closed loop pulsating heat pipe with alternating superhydrophobic channels. In Proceedings of the Joint 19th IHPC and 13th IHPS, Pisa, Italy, 10-14 June 2018.

26. Hao, T.; Ma, X.; Lan, Z.; Li, N.; Zhao, Y.; Ma, H. Effects of hydrophilic surface on heat transfer performance and oscillating motion for an oscillating heat pipe. Int. J. Heat Mass Transf. 2014, 72, 50-65. [CrossRef]

(C) 2020 by the authors. Licensee MDPI, Basel, Switzerland. This article is an open access article distributed under the terms and conditions of the Creative Commons Attribution (CC BY) license (http://creativecommons.org/licenses/by/4.0/). 